\title{
CERAMIC COATING FOR CORROSION (C3) RESISTANCE OF NUCLEAR FUEL CLADDING
}

Ece Alat ${ }^{a}$, Arthur T. Motta ${ }^{a, b}$, Robert J. Comstock ${ }^{c}$, Jonna M. Partezana ${ }^{c}$, and Douglas E. Wolfe ${ }^{\text {a,d,** }}$

${ }^{a}$ Department of Materials Science and Engineering, The Pennsylvania State University, University Park, PA 16802, USA

${ }^{b}$ Department of Mechanical and Nuclear Engineering, The Pennsylvania State University, University Park, PA 16802, USA

${ }^{c}$ Westinghouse Electric Co., 1340 Beulah Rd, Pittsburgh, PA, USA

${ }^{d}$ Applied Research Laboratory, The Pennsylvania State University, 119 Materials Research Building, University Park, PA 16802, USA

\begin{abstract}
In an attempt to develop a nuclear fuel cladding that is more tolerant to loss-of-coolant-accidents (LOCA), ceramic coatings were deposited onto a ZIRLO ${ }^{\text {TM }}{ }^{1}$ substrate by cathodic arc physical vapor deposition (CA-PVD). The coatings consisted of either $\operatorname{Ti}_{1-x} \mathrm{Al}_{\mathrm{x}} \mathrm{N}$ or TiN ceramic monolithic layers with a titanium bond coating layer as the interlayer between the ceramic coating and the ZIRLO ${ }^{\mathrm{TM}}$ substrate to improve coating adhesion. Several coating deposition trials were performed investigating the effects of bond coating thickness $(200-800 \mathrm{~nm})$, ceramic coating thickness $(4,8$ and $12 \mu \mathrm{m})$, substrate surface roughness prior to deposition, and select coating deposition processing parameters, such as nitrogen partial pressure and substrate bias, in

* Corresponding author. Tel.: +1 814865 0316, E-mail address: dew125@arl.psu.edu (D. E. Wolfe)

${ }^{1}$ ZIRLO is a trademark of Westinghouse Electric Co.


order to optimize the coating durability in a corrosion environment. Corrosion tests were performed in static pure water at $360^{\circ} \mathrm{C}$ and saturation pressure $(18.7 \mathrm{MPa})$ for 3 days. The optimized nitride-based ceramic coatings survived the autoclave test exposure showing very low weight gain of $1-5 \mathrm{mg} / \mathrm{dm}^{2}$ compared to the uncoated ZIRLO ${ }^{\mathrm{TM}}$ samples which showed an average weight gain of $14.4 \mathrm{mg} / \mathrm{dm}^{2}$. Post-corrosion exposure analytical characterization showed that aluminum depletion occurred in the TiAlN coated samples during the autoclave corrosion test, which led to the formation of the boehmite phase that degraded the corrosion durability of some of the TiAlN samples. However, by eliminating the aluminum content and depositing TiN, the boehmite phase was prevented from forming. Results are discussed in terms of the capability of $\mathrm{TiN}$ and $\mathrm{Ti}_{1-\mathrm{x}} \mathrm{Al}_{\mathrm{x}} \mathrm{N}$ coatings to improve the high temperature corrosion resistance and oxidation resistance of zirconium alloy cladding. 


\section{Introduction}

Zirconium-based alloys are currently used as structural components and as nuclear fuel cladding in nuclear power reactors because of their low neutron absorption cross section, resistance to high temperature steam corrosion, good thermal conductivity, good mechanical properties and resistance to void swelling $[1,2]$. However, under normal operating conditions zirconium-based nuclear fuel cladding alloys undergo waterside corrosion by the primary coolant water. A fraction of the hydrogen generated in the corrosion reaction, as shown in Eq. (1), may be picked up in the cladding and precipitate as hydrides which can lead to cladding embrittlement [3].

$$
\mathrm{Zr}+2 \mathrm{H}_{2} \mathrm{O}=>\mathrm{ZrO}_{2}+2 \mathrm{H}_{2}
$$

In the case of a loss-of-coolant-accident (LOCA), the cladding temperature may increase above $1200^{\circ} \mathrm{C}$ when the corrosion reactions and corresponding hydrogen generation are significantly accelerated. The large amount of hydrogen generated during the Fukushima-Daichii accident during the 2011 Japan earthquake and tsunami caused explosions in the reactor building, which severely worsened the accident development [4]. The Fukushima-Daichii accident has motivated research into Accident Tolerant Fuels (ATF), conceived as fuels that are more forgiving in the case of a loss-of-coolant accident, such that these fuels may increase the coping time to allow external intervention before severe fuel damage occurs. Current advanced cladding concepts include bulk silicon carbide (SiC) [5], bulk ferritic alloy steel cladding [6], and others [7]. Although they have the potential to ameliorate LOCA response, these concepts represent major engineering design changes to the reactor cores. An alternative approach is to create a protective coating layer that would improve the corrosion characteristics of the currently used zirconiumbased claddings without requiring a major change in cladding material. This approach would also 
have the benefit of reducing corrosion and hydrogen pickup during normal operation, further improving design safety.

Clearly there are many challenges to developing a nuclear fuel cladding coating that is safe, effective, and economic, as the coated system must also have a variety of essential properties: adherence to the substrate, thermal stability to high temperature with maximum oxidation resistance, resistance to scratching/gauging and resistance to radiation damage.

In this study we show the initial steps towards creating a protective coating of TiAlN on ZIRLO $^{\mathrm{TM}}$, with the focus on optimizing the coating layer thickness, substrate surface roughness, coating composition and cathodic arc physical vapor deposition (CA-PVD) processing parameters such as $\mathrm{N}_{2}$ partial pressure and substrate bias, to achieve high temperature corrosion resistant coatings that are well adherent and protective of the underlying ZIRLO ${ }^{\mathrm{TM}}$ substrate.

TiN and TiAlN coatings have been widely used for years on high-speed tool steels, cemented carbides, and cermet substrates for various cutting and finishing operations in the tooling industry [8-15]. In terms of corrosion resistance, TiN provides good chemical inertness [16] up to $600^{\circ} \mathrm{C}[15]$ depending on the metal to nitrogen ratio (stoichiometry). Titanium aluminum nitride (TiAlN), formed by incorporation of $\mathrm{Al}$ into TiN, is an ideal coating candidate for high temperature oxidation resistance and improved wear/abrasion resistance and toughness under extreme environments. The ternary nitrides composed of a combination of two binary nitrides can produce coatings with properties which exceed that of the individual binary coatings (i.e., solid solution hardening). Titanium nitride and aluminum nitride nano domains co-exist in $\mathrm{Ti}_{1}$ ${ }_{x} \mathrm{Al}_{\mathrm{x}} \mathrm{N}$ for $0.7>\mathrm{x}>0.6$ which improve the coating mechanical properties by significantly increasing the hardness and Young's modulus of the material $[15,17]$. It further improves the 
oxidation/corrosion resistance (upwards of $800-1000^{\circ} \mathrm{C}$ ), improves thermal stability, improves wear/abrasion resistance and toughness $[8,15,18-20]$. The increased corrosion resistance is due to the formation of a dense $\mathrm{Al}_{2} \mathrm{O}_{3}$ layer that reduces outward aluminum diffusion and inward oxygen diffusion in the protective film [15]. In principle, during corrosion at high temperature aluminum diffuses to the surface and reacts with oxygen to form a thin protective oxidation barrier $\left(\mathrm{Al}_{2} \mathrm{O}_{3}\right)$ which significantly improves the oxidation performance as oxygen diffusion through aluminum oxide is several orders of magnitude slower than through zirconium oxide. Moreover, previous studies also showed that oxidation initiation depends on the aluminum content of the TiAlN coating, thus increasing the aluminum content leads to an increase in the oxidation resistance [21]. Several other factors that contribute to the corrosion resistance of the TiAlN coatings include microstructure, residual stress and extreme environmental conditions. To date, there has only been one study to assess the oxidation resistance of $\operatorname{TiN}$ and $\mathrm{Ti}_{0.35} \mathrm{Al}_{0.65} \mathrm{~N}$ coatings on $\mathrm{Zr}-4$ substrates, in which the coatings were deposited by pulsed lased deposition (PLD) and tested at $500^{\circ} \mathrm{C}$ [16]. In the current study, as a first step to establish ATF, the coating has been tested at normal plant conditions to ensure that no degradation occurs during normal operation. For the LOCA conditions, in which temperatures can reach up to $1200^{\circ} \mathrm{C}$, elemental doping will be considered to further improve the corrosion/oxidation resistance of the coatings, which will be presented in a future paper.

A key part of producing a durable coating is achieving strong adhesion to the substrate, which can be obtained by the application of an interlayer (bond coating) between the coating and the substrate [12,15,17,22-24]. The main reason for improved adhesion and coating system performance is the dissolution of substrate oxides (gettering effect) and the accommodation of high compressive coating residual stress across the coating substrate interface from the 
deposition process $[23,24]$. The use of titanium as a bond coating and its effect on coating performance were studied before for TiN coatings on various stainless steel substrates [23-26]. A study conducted by Bull et al. [23] demonstrated that adhesion improved in TiN coatings deposited by plasma assisted chemical vapor deposition (PACVD) and PVD as Ti interlayer thickness increased. However, no work has been done to investigate the effects of Ti interlayer deposited by CA-PVD between either a TiAIN coating or a TiN coating and its thickness on the corrosion resistance of ZIRLO ${ }^{\mathrm{TM}}$ substrates. Compared to other PVD techniques, depositing species in CA-PVD have higher kinetic energies leading to higher compressive stresses, and these values are affected by various parameters including the type of coating and the coating thickness. Hence, the bond layer thickness should be tailored according to the type of substrate, type of coating and coating thickness in order to be able to absorb stresses associated with the coating formed during the deposition and operation. If the bond coat is too thin, it cannot absorb extrinsic (thermal) stresses associated with coating degradation exposed to extreme environmental conditions such as oxidation, moisture, or elevated temperatures.

Additionally, Wang et al.[22] pointed out the importance of thermal expansion coefficient matching to achieve better adhesion between the substrate and the coating, claiming that a large mismatch between the thermal expansion coefficients in between them will result in poor adhesion. Accordingly, in choosing the interlayer material, one has to consider thermal expansion coefficients of the substrate and the coating material. In the case of TiAlN and TiN coatings deposited by cathodic arc evaporator, the coefficient of thermal expansion (CTE) of TiAlN was determined to be $7.5 \times 10^{-6} \mathrm{~K}^{-1}$ while that of TiN is $9.4 \times 10^{-6} \mathrm{~K}^{-1}$ [22]. Previous studies showed that thermal expansion behavior of ZIRLO ${ }^{\text {TM }}$ and Zircaloy-4 is similar for the temperature range of $290-400^{\circ} \mathrm{C}$ [27]. Accordingly, CTE of ZIRLO ${ }^{\mathrm{TM}}$ can be assumed to be $\sim 6.3$ 
$\times 10^{-6} \mathrm{~K}^{-1}$ at $360^{\circ} \mathrm{C}$ [28]. Therefore, application of a titanium bond coating would be expected to improve adhesion since its CTE of $8.5 \times 10^{-6} \mathrm{~K}^{-1}$ (at room temperature) [29], lies in between that of the substrate and the coating.

In addition, different coating process parameters such as substrate temperature, bias voltage, arc current and nitrogen pressure allow the coating properties to be tailored for application-specific use in extreme environments [30-32]. This study focuses on improving TiN and TiAlN coating properties through a systematic investigation of the effect of bias voltage, $\mathrm{N}_{2}$ partial pressure and cathode composition on arc deposited coating properties $[9,15]$. The substrate bias affects film microstructure, coating composition (Al content in TiAlN coating), impinging ion energy on the growing film (i.e., residual stress, density) which leads to a denser coating, backscattering of target atoms, and surface texture $[9,15,19,32]$. Another effect of bias voltage is related to the reaction kinetics; a high bias voltage results in increased substrate surface temperature, thus increasing the kinetic energy of ions which facilitates the chemical reaction $\left(\mathrm{Ti}+1 / 2 \mathrm{~N}_{2} \rightarrow \mathrm{TiN}\right)$ by overcoming the activation barrier at much lower temperatures as compared to standard equilibrium conditions [25]. Additionally, nitrogen content (i.e., partial pressure) affects the coating composition, crystallography, hardness, toughness, wear/abrasion performance and degree of adhesion $[9,33]$.

This study investigates the effects of all these parameters on coating adhesion and corrosion performance. 


\section{Experimental Methods}

\subsection{Materials and Coating}

$\mathrm{Ti}_{1-\mathrm{x}} \mathrm{Al}_{\mathrm{x}} \mathrm{N}$ (where $\mathrm{x} \sim 0.54-0.67$ ) and $\mathrm{TiN}$ [henceforth referred to as (TiAlN or TiN), respectively] coatings were deposited onto ZIRLO ${ }^{\mathrm{TM}}$ coupons using cathodic arc physical vapor deposition (CA-PVD). ZIRLO ${ }^{\mathrm{TM}}$ was provided by Westinghouse in the form of cold-worked stress-relieved sheet material of the typical clad thickness ( $\sim 600$ microns) with the usual fabrication texture in which the basal poles are preferentially oriented in the normal or radial direction. The chemical composition of ZIRLO ${ }^{\mathrm{TM}}$ is nominally $1 \% \mathrm{Nb}, 1 \% \mathrm{Sn}, 300-600$ wt ppm Fe and balance Zr. The ZIRLO $^{\text {TM }}$ sheets were cut into coupons $(2.54 \mathrm{~cm} \times 5.08 \mathrm{~cm} \times 0.043 \mathrm{~cm})$ for subsequent coating surface preparation, deposition and corrosion testing. Each coupon had a small hole (1.6 mm) drilled near one end, and which was used for hanging the coupons in an autoclave tree during corrosion testing. The coupons were prepared by hand grinding the edges and corners with 240 grit $\mathrm{SiC}$ paper and the surfaces with 240,600 , and 800 grit $\mathrm{SiC}$ paper in that sequence to obtain the desired surface roughness of 0.1-0.875 $\mu \mathrm{m}$ (4-35 microinch). The samples were then cleaned in an ultrasonic cleaner with acetone for 10 minutes, deionized water rinse, followed by ultrasonic cleaning for 10 minutes in methanol, deionized water rinse and nitrogen gas blow dry. Roughness measurements were done using a SJ-201P Surface Roughness Tester.

\subsection{Coating Deposition}

All the coatings in the current study were deposited using cathodic arc physical vapor deposition (CA-PVD) which can be scaled to production-sized components. The term PVD denotes those vacuum deposition processes where the coating material is evaporated or removed by various 
mechanisms (resistant heating, ablation, high-energy ionized gas bombardment, or electron gun), and the vapor phase is transported to the substrate forming a coating. In the CA-PVD process, a continuous or pulsed high current-density, low voltage electric current is passed between two separate electrodes (cathode and anode) under low pressure vacuum, vaporizing the cathode material while simultaneously ionizing the vapor, forming a plasma. The high current density (usually $10^{4}-10^{6} \mathrm{~A} / \mathrm{cm}^{2}$ ) causes arc erosion by vaporization and melting while ejecting molten solid particles from the cathode surface, with a high percentage of the vaporized species being ionized with elevated energy (50-150 eV) and causing some species to be multiply charged.

In the case of TiAlN, as the material vaporized from the titanium-aluminum (cathode target) passes through the arc it becomes ionized, forming a plasma. The plasma is directed towards the substrate's surface, and in the presence of nitrogen, forms a TiAlN coating. The kinetic energies of the depositing species in cathodic arc are much greater than those of other PVD processes. Therefore, the plasma becomes highly reactive as a greater percentage of the vapor is ionized. In addition, the cathodic arc process allows tailoring of the interfacial products, especially in multilayer coatings, and does not produce a distinct coating/substrate interface [15]. As a result of the high kinetic energy, CA-PVD coating residual stresses are generally compressive [30,34], which can be controlled by deposition parameters [30,35]. These compressive stresses can prevent the formation and propagation of cracks in the coating. Moreover, in order to minimize thermal expansion mismatch based stresses, the PVD process is performed at $200^{\circ} \mathrm{C}-500^{\circ} \mathrm{C}$ [36,37]. High vacuum pressures are commonly required for PVD techniques to achieve the large mean free path which makes evaporated atoms travel from the source material to the substrate in a straight path (“line-of-sight” process) [36,37]. 
The main disadvantage of CA-PVD is the metal macro particle production due to either droplet formation because of low melting point materials ( $\mathrm{Al}$ in case of TiAlN) during arc evaporation or intense, localized heating by the arc, which become entrapped within the depositing coating and serve as stress concentrators and crack initiation sites or incompletely ionized excess atoms that coalesce to macro particles during flight towards the substrate $[9,15,36]$. Several methods that were previously applied to decrease these macro particles include application of a straight duct particle filter [22] and plasma refining by electromagnetic field, which avoid deposition of larger macro particles on the substrate [19].

In the current study, the CA-PVD process was performed in a chamber with dimensions of 50.8 $\mathrm{cm} \times 50.8 \mathrm{~cm} \times 50.8 \mathrm{~cm}$. For the coating deposition process two cathodes of different composition were used: dished high purity (99.999\%) elemental titanium (for the bond coating) and titanium aluminum (33at.\%Ti-67at.\%Al) for the top coating to enhance corrosion protection at elevated temperature), which were individually evaporated by Miller XMT 304 CC/CV DC welder power supplies. These cathodes were cylindrical with a diameter of $6.3 \mathrm{~cm}$ and a thickness of $3.2 \mathrm{~cm}$ and were oriented $180^{\circ}$ from each other with the ZIRLOTM coupons located between the cathodes with a spacing of $22.9 \mathrm{~cm}$. The plasma density and location were controlled by placing magnets behind the cathode targets. The samples were mounted in sample holders which were in turn mounted on an 8-post planetary rotation setup with shadow bars along the edge of each sample to avoid increased coating buildup along the sample edges. All faces and edges of each sample were coated except for the region mounted in the sample holder. The substrate coupon temperature was $325^{\circ} \mathrm{C}$ during coating deposition, as measured by thermocouples placed inside the deposition chamber. 
At the cathode vaporization stage, $1.6 \times 10^{-3} \mathrm{~Pa}$ Ar atmosphere and $-1000 \mathrm{~V}$ bias were applied to remove the native oxide from the substrate surface and improve coating adhesion. The ion preheat time used was 5 minutes total. The deposition was conducted in two steps: bond layer deposition under Ar atmosphere using only the titanium cathode, followed by either TiAlN or TiN top coating reactive deposition performed under $\mathrm{N}_{2}$ atmosphere at an approximate deposition rate of $0.028 \mu \mathrm{m} / \mathrm{min}(1.68 \mu \mathrm{m} /$ hour $)$ by using only one titanium aluminum or titanium cathode target. The system is capable of using three sources simultaneously which could be used to double or triple the coating deposition rate, if needed.

The deposition parameters were systematically varied and grouped according to generations. In the first generation (GEN-1), the thickness of the bond coating was optimized by depositing and corrosion testing samples with titanium bond coating (BC) thicknesses values of 0.2, 0.4, 0.6 and $0.8 \mu \mathrm{m}$. In the second generation (GEN-2), both the ZIRLO ${ }^{\mathrm{TM}}$ coupon surface roughness before deposition $(0.1$ to $0.875 \mu \mathrm{m})$ and total coating thickness (4 to $12 \mu \mathrm{m})$ were evaluated for their impact on corrosion performance. The primary variable investigated in generation 3 (GEN-3) samples was composition, i.e., removing the aluminum content from TiAlN to form TiN to determine its resistance to forming the boehmite phase $(\mathrm{AlO}(\mathrm{OH})$, typical composition: 44.98 wt.\%Al, $1.68 \mathrm{wt} . \% \mathrm{H}$, and $53.34 \mathrm{wt} \% \mathrm{O}$ ) [39]. The deposition parameters for the three generations of coatings are summarized in Table 1.

\subsection{Corrosion Testing}

Corrosion testing was performed at Westinghouse in a static autoclave in pure water for 3 days at $360^{\circ} \mathrm{C}$ and saturation pressure, corresponding to $18.7 \mathrm{MPa}$ at this temperature. Weight gain measurements were performed following the autoclave test to assess the coating durability and 
corrosion resistance. Post-autoclave coatings were analyzed by X-ray diffraction (XRD), optical microscopy (OM), scanning electron microscopy (SEM) and energy dispersive X-ray spectroscopy (EDS). Both surface and cross-section analyses were performed. Surface analyses were conducted directly after the autoclave test without any surface treatment to preserve the surface integrity. Analyses of coating cross section samples were conducted after cutting samples into half, mounting in cold mount epoxy, grinding and polishing. XRD studies were conducted on a PANalytical XPert Pro Multi-Purpose Diffractometer (MPD) instrument with $240 \mathrm{~mm}$ radius, fixed divergence slit $\left(0.25^{\circ}\right)$, receiving slit $\left(0.25^{\circ}\right), \mathrm{Cu} \quad \mathrm{K}_{\alpha} \quad\left(\mathrm{K}_{\alpha} 1=1.54056 \AA\right.$, $\mathrm{K}_{\alpha} 2=1.54443 \AA$ ) radiation. Bragg-Brentano scans were performed with a step size of $0.026^{\circ}$ twotheta. Backscatter and secondary electron scanning electron microscopy (SEM) measurements were conducted using a FEI Quanta 200 Environmental SEM at 80 Pa pressure and $20 \mathrm{kV}$ high voltage. 


\section{Results and discussion}

\subsection{GEN-1: Ti Bond Coating Thickness}

As stated above, the bond coating can have a significant effect on the top coating adhesion and coating system performance as it can dissolve substrate oxides promoting adhesion as well as accommodate high compressive residual stress from the deposition technique due to its compliancy. If the bond coat is too thin, it cannot absorb extrinsic stresses associated with coating degradation exposed to extreme environmental conditions such as oxidation or moisture. The effect of titanium bond coating thickness on total coating system corrosion resistance was investigated by depositing various Ti BC thicknesses. Thicknesses of 0.2 (E1), 0.4 (E2), 0.6 (E3) and $0.8(\mathrm{E} 4) \mu \mathrm{m}$ were achieved with a deposition times of $6,8,10,15 \mathrm{~min}$ respectively, as previously shown in Table 1, which indicates a proportionality between the deposition time and the coating thickness. After Ti BC deposition, a TiAlN coating with a thickness of $\sim 13 \mu \mathrm{m}$ was deposited and these samples were then subjected to the corrosion testing. The weight gain data collected after the corrosion testing for these samples is presented in Figure 1. The samples with 0.2 and $0.4 \mu \mathrm{m}$ bond coat thickness suffered weight loss, indicating an unstable coating layer in which coating delamination occurred during corrosion. The thicker bond coating samples showed better behavior: the average weight gain of both thicker $(0.6$ and $0.8 \mu \mathrm{m})$ bond coat samples was minimal compared to that of the uncoated ZIRLOTM sample. The $0.8 \mu \mathrm{m}$ bond coating thickness showed a positive weight gain of only $3 \mathrm{mg} / \mathrm{dm}^{2}$ and no indication of coating spallation under visual inspection while the $0.6 \mu \mathrm{m}$ samples showed a similarly low average weight gain without spallation. The absence of delamination and the minimal weight gain 
indicate that these bond layer/coating thickness value combinations provided good protection for increased durability against cladding corrosion under the autoclave conditions selected.

SEM analysis was conducted to further investigate the coating performance and durability after corrosion test exposure. The SEM surface micrographs presented in Figure 2 are all from a sample with a bond coating thickness of $0.6 \mu \mathrm{m}$ showing areas of coating failure (Figure 2a and $2 b)$ and areas where the coating was intact (2c). The overall weight gain data was negative for this particular sample, which was confirmed by the presence of coating spallation. However, Figure 2 provides good insight into the surface morphology of the TiAlN-based coatings after 3 days of exposure when the bond coating is applied to the desired requirements and what occurs when the bond coat is not optimized for subsequent coating deposition. SEM examination confirms that there were delaminated regions, indicating poor coating adhesion; cracks were observed around delaminated regions which are attributed to stresses caused by oxide formation of the underlying ZIRLO ${ }^{\mathrm{TM}}$ substrate.

Visual inspection of the samples with a thicker bond coating show no delamination, which, combined with low weight gain, resulted in the $0.6 \mu \mathrm{m} \mathrm{BC}$ being selected for further optimization of the TiAlN/TiN coating system in subsequent coating generations. Delamination was observed on certain $0.6 \mu \mathrm{m}$ samples which was determined to be due to poor sample preparation, other samples showed no delamination, indicating that $0.6 \mu \mathrm{m}$ is close to the optimal thickness required to form a good adhesion layer for the deposition conditions studied.

To determine the phases present in the coating layers and to further evaluate the coating performance after corrosion exposure, $\mathrm{x}$-ray diffraction analysis was performed. Figure 3 shows the x-ray diffraction patterns of uncoated ZIRLO ${ }^{\mathrm{TM}}$ (Fig. 3a), TiAlN in the as deposited 
condition (Fig.3b), and after 3 days of autoclave exposure (Fig.3c). The XRD results in Fig. 3a are consistent with the uncoated ZIRLO ${ }^{\text {TM }}$ (ICDD PDF\# 00-005-0665) exhibiting the hexagonal closed packed crystal structure with prevailing basal fabrication texture, leading to a high intensity of the (0002) peak. Figure $3 \mathrm{~b}$ shows the XRD pattern of coated ZIRLO ${ }^{\mathrm{TM}}$ in the asdeposited condition, with a $0.6 \mu \mathrm{m}$ Ti BC layer, followed by a $\sim 13 \mu \mathrm{m}$ thick TiAlN layer. The XRD peaks can be indexed as, a TiAlN cubic rocksalt structure with a lattice parameter of 0.42 nm $\left(\mathrm{Ti}_{0.5} \mathrm{Al}_{0.5} \mathrm{~N}\right.$, ICDD PDF\# 04-005-5251). Accordingly, Energy Dispersive Spectroscopy (EDS) analysis showed that the coating composition was $\mathrm{Ti}_{1-x} \mathrm{Al}_{x} \mathrm{~N}$, in the as deposited condition where $\mathrm{x}=0.54-0.67$ depending on deposition conditions. Moreover, crystallite size is determined to be ranging between $77-80 \AA$.

Figure 3c shows the XRD pattern of the same sample after corrosion testing in which new phases formed. The new peaks were indexed and identified as belonging to the anatase (ICDD PDF\# 04002-8296) and boehmite phases (ICDD PDF\# 00-021-1307) when combined with EDS data. The presence of these phases in Figure $3 \mathrm{c}$ indicates a possible degradation mechanism of the TiAlN coating in which aluminum diffuses to the outer surface where it reacts with water under autoclave conditions. Previously, Khatkhatay et al. [16] also determined anatase phase formation in case of $\mathrm{Ti}_{0.35} \mathrm{Al}_{0.65} \mathrm{~N}$ coatings deposited by pulsed laser deposition after corrosion testing at $500^{\circ} \mathrm{C}$ and $25 \mathrm{MPa}$ for $48 \mathrm{~h}$. Although, the coating composition and corrosion test condition in this study were different, anatase phase formation was also observed at the XRD pattern of the current study; however, different from the results presented in the study of Khatkhatay et al., boehmite phase formation was observed. For aluminum, the boehmite phase is sometimes produced in the form of a corrosion resistant layer to protect an underlying metallic aluminum 
alloy [40,41]. On the contrary, in this study, boehmite formation did not occur on a pure aluminum substrate but occurred on the TiAlN coating surface.

In the as-coated XRD pattern (Fig.3b), a slight shift to higher angles in the TiAlN peak was observed, possibly indicating compressive strains in the coating as has been previously observed for TiAlN coatings deposited by CA-PVD process [34]. Part of the stresses in the sample are intrinsic residual stresses associated with the CA-PVD process, which are due to the higher energy of the ionic species bombarding the substrate during deposition. There are also stress contributions due to compositional variations and differences in thermal expansion. Thus, extrinsic residual stress $(190 \mathrm{MPa})$ occurred upon cooling to room temperature from the deposition temperature $\left(325^{\circ} \mathrm{C}\right)$ and thermal expansion mismatch between the TiAlN and ZIRLO $^{\text {TM }}$ as calculated for $v=0.23$ [42] and $E=406.5$ [36]; which is tensile since TiAlN has a higher CTE than ZIRLO ${ }^{\text {TM }}$. Additionally, there was a slight shift of the Zr peaks towards lower $2 \theta$ values, again possibly indicating tensile strains which is attributed to the balancing of the coating compressive strains. After the autoclave test, it was determined that TiAlN, anatase and most of the boehmite phase peaks shifted towards lower $2 \theta$ values as compared to the literature (unstressed) values, indicating tensile strains in the newly formed phases, possibly caused by strain relaxation as a result of aluminum depletion during autoclave testing and the extrinsic residual stress occurred upon cooling from the autoclave test temperature to room temperature which is determined to be $210 \mathrm{MPa}$. It is also possible that the peak shift is caused by variations in composition in the phases studied.

The main results of the first generation were: 
- A $0.6 \mu \mathrm{m}$ thick Ti bond coating between the ZIRLO ${ }^{\mathrm{TM}}$ substrate and the TiAlN top coating is enough to achieve good layer adhesion to the substrate and corrosion resistant coating performance.

- Boehmite phase with non-uniform distribution forms on top of TiAlN coatings as a result of outward migration of aluminum after 3 days of autoclave test at $360^{\circ} \mathrm{C}$ and $18.7 \mathrm{MPa}$.

- Although boehmite phase formation was observed, TiAlN coating was determined to provide good protection against corrosion of $\mathrm{Zr}$ alloys according to an order of magnitude decrease in the weight gain data compared to the uncoated ZIRLO ${ }^{\mathrm{TM}}$.

\subsection{GEN-2: Surface Roughness and Coating Thickness}

PVD coatings containing high levels of compressive stress often result in poor coating durability if the deposited coating thickness exceeds 12 microns, as the internal intrinsic coating stresses can often exceed the interfacial adhesion strength. This results in a lower critical load for coating spallation. The occurrence of this phenomenon depends on multiple factors, including environment, temperature, material systems, microstructure and design architecture. In general, a rougher substrate results in better coating adhesion, as there is a larger number of atomic bonds for a rougher substrate as compared to a smooth substrate. Improved coating adhesion results from the mechanical interlocking of the layer on the rougher substrate.

Second generation coatings investigated the influence of ZIRLO ${ }^{\mathrm{TM}}$ substrate surface roughness $\left(\mathrm{R}_{\mathrm{a}}\right)$ and TiAlN coating layer thickness on corrosion resistance. To investigate the substrate surface roughness effect on coating durability, ZIRLO ${ }^{\mathrm{TM}}$ substrate surface roughness values of $0.1,0.25,0.5$ and $0.875 \mu \mathrm{m} \mathrm{R}_{\mathrm{a}}$ were prepared prior to coating deposition. Additionally, to investigate the effect of the TiAlN top coat thickness on corrosion resistance coatings with 4,8 
and $12 \mu \mathrm{m}$ thickness were deposited on $\mathrm{ZIRLO}^{\mathrm{TM}}$ substrate coupons (with fixed $0.6 \mu \mathrm{m}$ Ti BC thickness layer). As an example to demonstrate the appearance of substrate surface with different roughness, optical microscopy images of the polished cross sections for samples (E10 and E12) with $0.25 \mu \mathrm{m} \mathrm{R}_{\mathrm{a}}$ and $0.875 \mu \mathrm{m} \mathrm{R}_{\mathrm{a}}$ in the as deposited state (before autoclave testing) are presented in Figure $4 \mathrm{a}$ and $4 \mathrm{~b}$, respectively, where the difference in substrate surface roughness is evident.

After the autoclave test, the sample weight gain was measured to evaluate the effect of surface roughness and optimum coating thickness on corrosion resistance, which is presented in Figure 5. The weight gain data demonstrated that although samples with various coating thicknesses and a $0.875 \mu \mathrm{m}$ substrate surface roughness prior to the autoclave test showed no delamination they showed the highest weight gain compared to the samples with smaller substrate surface roughness. On the contrary, samples with 0.1 and $0.5 \mu \mathrm{m} \mathrm{R}_{\mathrm{a}}$, showed negative weight gain, indicating coating delamination. The exact mechanism of this delamination is not known, but the authors have attributed it to the stresses associated with non-uniform boehmite phase formation, which can be observed in Figure 6a and b. SEM analyses revealed that the boehmite $(\mathrm{AlO}(\mathrm{OH}))$ phase appears to have grown on the outer surface, above the TiAlN coating and its thickness is not uniform, reaching up to $\sim 5 \mu \mathrm{m}$ in certain regions of the coating. The lowest weight gain and no delamination was obtained with $0.25 \mu \mathrm{m} \mathrm{R}_{\mathrm{a}}$ substrate surface roughness, so this was the surface roughness chosen as the optimal value. Among the samples with $0.25 \mu \mathrm{m} \mathrm{R}_{\mathrm{a}}$, the lowest weight gain was obtained in the sample with coating thickness of $12 \mu \mathrm{m}$ so this was chosen as the optimum thickness value. 
The weight gain of uncoated ZIRLO ${ }^{\text {TM }}$ weight gain was $14.4 \mathrm{mg} / \mathrm{dm}^{2}$ after 3 days at $360^{\circ} \mathrm{C}$ and saturation pressure in agreement with previous studies [43], which translates to about $1 \mu \mathrm{m}$ oxide thickness [44]. From the findings of the first generation, it was interpreted that the weight gain in the samples was due in large part to the existence of the boehmite phase, which forms according to the reaction:

$$
\mathrm{Al}+2 \mathrm{H}_{2} \mathrm{O} \rightarrow \mathrm{AlO}(\mathrm{OH})+3 / 2 \mathrm{H}_{2}
$$

Further examination was performed using EDS in order to determine the composition of the sample surface. EDS data presented in Figure 7a shows that the majority (regions a, $c$ and d) of both the white and dark regions on the TiAIN coated surface were rich in aluminum as evident by the higher aluminum to titanium ratio (greater than 2). In general, the white regions (see Figure 7) appeared to show a greater concentration of aluminum, but this is attributed to a greater volume of the boehmite phase changing (masking) the EDS interaction volume, thus changing the depth within the coating from which EDS data is obtained. These results suggest that aluminum depletion occurred within the TiAIN coating under the autoclave conditions studied, resulting in the formation of the boehmite phase when exposed to high temperature/pressure water during the autoclave test. To confirm aluminum migration, EDS map and line analysis of the polished cross sections were performed, as presented in Figure $7 \mathrm{~b}$ and $7 \mathrm{c}$, respectively. These images show a higher concentration of $\mathrm{Al}$ at the layer/water interface after corrosion, consistent with aluminum migration from the TiAlN coating. This Al has been shown to have migrated from the top $4 \mu \mathrm{m}$ TiAlN layer. The authors attributed aluminum migration mechanism to the aluminum diffusion occurring through the grain boundaries as in the case of $\mathrm{Al}$ diffusion in TiN [45]. 
The main results of the second generation were:

- The thickness of the boehmite phase formed is not uniform but appears to nucleate at grain boundaries.

- Despite the formation of boehmite phase during corrosion, the combination of a $0.25 \mu \mathrm{m}$ $\mathrm{R}_{\mathrm{a}}$ substrate surface roughness and a $12 \mu \mathrm{m}$ top coat layer thickness provide the optimum coating characteristics to obtain best adhesion for CA-PVD TiAlN coatings on ZIRLO ${ }^{\mathrm{TM}}$ substrates with Ti BC.

\subsection{GEN-3: Coating Process Parameters}

For GEN-3, in an effort to minimize or eliminate boehmite phase formation, cathodic arc deposition parameters were varied in order to improve the coating microstructure and properties for corrosion resistance. The effect of changes in nitrogen partial pressure, substrate bias, and coating composition (TiAlN versus TiN; i.e., eliminating the aluminum content) on corrosion behavior were investigated. Varying the coating parameters resulted in different weight gain data, as shown in Figure 8.

The effect of variation of coating deposition parameters is shown in Table 2 by adding the weight gain data to the parameters previously introduced in Table 1. Uncoated ZIRLO ${ }^{\mathrm{TM}}$ shown in Table 2 had $14.4 \mathrm{mg} / \mathrm{dm}^{2}$ weight gain after 3 days of autoclave test, $\mathrm{N}_{2}$ pressure was $1.6 \mathrm{~Pa}$ during coating deposition in GEN-1 and GEN-2. In the current generation, sample E18 was synthesized by increasing the $\mathrm{N}_{2}$ pressure slightly to $1.9 \mathrm{~Pa}$. Another sample (E19) was produced with both slightly increased $\mathrm{N}_{2}$ pressure $(1.9 \mathrm{~Pa})$ and increased substrate bias to $100 \mathrm{~V}$ from 50 
V. Coating thickness and the substrate surface roughness were kept at $\sim 12 \mu \mathrm{m}$ and $0.25 \mu \mathrm{m} \mathrm{R}_{\mathrm{a}}$ respectively.

Visual examination and SEM analysis showed that there was no delamination after the autoclave test in the samples coated with a slightly increased (1.9 Pa) $\mathrm{N}_{2}$ pressure, in agreement with a previous study conducted by Lin et al [9], which mentioned an increase in adhesion of TiAlN coatings deposited by CA-PVD as the $\mathrm{N}_{2}$ partial pressure increased from 1 to $5 \mathrm{MPa}$. However, this pressure change $(1.9 \mathrm{MPa})$ resulted in a higher average weight gain value of $17 \mathrm{mg} / \mathrm{dm}^{2}$, which is much larger than that measured for the sample (E14) having the same coating thickness and surface roughness, but deposited with 1.6 $\mathrm{Pa} \mathrm{N}_{2}$ pressure. The reason for this change in weight gain is unknown at this time, further investigation is needed.

The data presented in Table 2 also showed that increased substrate bias slightly improved corrosion resistance of the layers, as shown by the lower weight gain of $10.1 \mathrm{mg} / \mathrm{dm}^{2}$. This suggests that the increased bias resulted in a denser coating which provided increased resistance to corrosion. Previous studies on TiAlN coatings deposited by CA-PVD showed that increased bias results in decreased aluminum content $[19,46]$, which could lead to a lower amount of protective $\mathrm{Al}_{2} \mathrm{O}_{3}$ which is undesired for corrosion resistant coatings. In the current study, lower weight gain was obtained and this situation can be explained with similar reasoning. The weight gain was attributed to boehmite phase formation and accordingly it can be evaluated that the lower weight gain leads to less boehmite phase formation due to decreased aluminum content with increased bias. It is also possible that this lower weight gain can be attributed to the smoother surface texture [19], which can decrease the oxidation sites, increase compressive 
stresses [30], and modify the microstructure with fine grains with reduced porosity [47] which results in having a denser coating.

Table 2 shows select weight gain averages for GEN-3 coatings deposited as a function of nitrogen partial pressure and substrate bias. In general, a higher substrate bias results in a denser coating which was expected to minimize the formation of the boehmite phase by retarding aluminum migration. In addition, the increase in nitrogen partial pressure was expected to assist in modifying the metal/nitrogen ratio as it was believed that unreacted or lightly bound aluminum was diffusing to the coating surface and reacting with the water forming the boehmite phase. However, as shown in Table 2, changing the bias and the partial pressure of nitrogen showed mixed results with regards to weight gain and the effects on corrosion are indeterminable. The variation in the corrosion weight gain results is attributed to a combination of weight loss due to coating spallation and weight gain due to the boehmite formation for previous generations, making direct comparison difficult. Further studies are required to confirm the relative impact of coating processing parameters and optimization of the corrosion performance of these coatings.

Previously Korablov [48] claimed that PVD TiAlN with Ti/Al=55 at $\%$ was composed of a high amount of AlN that can be hydrolyzed in water easily and demonstrated the existence of the boehmite phase after $3 \mathrm{~h}$ exposure to water at $300^{\circ} \mathrm{C}$, however no information was provided about the nucleation and growth mechanism of the boehmite phase. Abid [49] observed the formation of boehmite phase on AIN PVD thin film surface upon reacting with boiling water, however no information was also given about the nucleation and growth mechanisms. Hart [41] provided some explanation for the nucleation and growth mechanisms of boehmite formed on 
pure aluminum sample due to reaction with water and said that boehmite nucleated at dislocation centers on amorphous oxide barrier film, which is followed by the film thickening by ionic diffusion through the oxide. Accordingly, although the exact nucleation and growth mechanism of the boehmite phase on the TiAlN is still not completely understood, it is believed to be initiated at the $\mathrm{Ti}_{1-\mathrm{x}} \mathrm{Al}_{\mathrm{x}} \mathrm{N}$ grain boundaries which are rich in aluminum due to aluminum diffusion. This is supported by the appearance of non-uniform growth on the surface of the $\mathrm{Ti}_{1-}$ ${ }_{x} \mathrm{Al}_{\mathrm{x}} \mathrm{N}$ in which there appears to be a pattern to the boehmite phase formation. The authors suspect that the larger boehmite regions are the sites where aluminum migration first occurred and reacted with the water to form boehmite which then grew with increased exposure. With increasing test duration, aluminum migration continued due to the chemical potential gradient within the Al depleted region of the TiAlN coating. However, this mechanism needs to be verified by performing a systematic study of autoclave testing and transmission electron microscopy analysis. SEM images in Figure 9-(b) support this reasoning in which there appears to be localized nucleation and growth on the TiAlN coating surface. This hypothesis is further supported from the literature in that boehmite has been shown to nucleate at grain boundaries for pure aluminum metal at elevated temperature [36].

The last parameter tested in GEN-3 was that samples were prepared with an external layer of TiN deposited by CA-PVD to evaluate its ability to stop Al migration and boehmite phase formation. As shown in Figure 8, TiN had the lowest weight gain of $1.2 \mathrm{mg} / \mathrm{dm}^{2}$ in average after the autoclave test, with no delamination and correspondingly a significant improvement in the corrosion resistance. An SEM analysis on surface and cross sections of the TiN coated samples is presented in Figure 10, showing that there was no outward migration of $\mathrm{Al}$ and no boehmite phase formation. Further, coatings with a TiN outer layer remained intact with no indication of 
coating debonding and/or oxygen penetration through the coating. This strongly suggests that TiN is a corrosion resistant layer to protect the ZIRLO ${ }^{\text {TM }}$ substrate, which supports the conclusion that was reached by Khatkhatay et al. [16] for TiN coatings deposited on Zr-4 substrate.

The main results of the GEN-3 study are:

- An increase in nitrogen partial pressure showed a slight degradation of properties of the coating for the deposition conditions studied.

- An increase in substrate bias slightly improves corrosion resistance, but the magnitude of the change is less than that effected by a change in nitrogen partial pressure for the deposition condition studied.

- An outer layer of TiN coating, was shown to be effective in stopping Al migration and boehmite phase formation.

The results of this initial study provides a set of parameters and conditions that optimize the resistance of the deposited layer to autoclave corrosion. Finally, we should mention that the neutronic effect of the layers used was evaluated and found to be quite small for the layer thicknesses and compositions studied [50], giving confidence that this is a promising approach to creating an accident tolerant fuel.

\section{Conclusion}

In this study, TiAIN and TiN monolayer ceramic coatings were applied to ZIRLO ${ }^{\mathrm{TM}}$ coupons to improve corrosion resistance in high temperature water. Both types of coatings adhered well to ZIRLO $^{\mathrm{TM}}$ with proper surface preparation and with an application of a Ti bond coating layer of 
the proper thickness. Coating parameters were optimized to achieve a coating that would withstand 3 days at $360^{\circ} \mathrm{C}$ with minimal weight gain, and no penetration of oxygen, no cracking, and no debonding. A Ti bond layer with $0.6 \mu \mathrm{m}$ thickness and a substrate surface roughness of $0.25 \mu \mathrm{m} \mathrm{R}$ a provided the smallest weight gain. However, XRD, SEM and EDS measurements showed that there was some egress of $\mathrm{Al}$ in TiAlN coatings, which reacted with water and caused the formation of the boehmite phase. In comparison, boehmite phase formation was not observed in TiN coated samples since outward migration of aluminum was suppressed.

We conclude that a TiAlN CA-PVD layer with an outer TiN layer can be effective in increasing corrosion resistance of ZIRLO, as long as the optimal surface bond coat, layer thickness, surface roughness, $\mathrm{N}_{2}$ pressure and bias are applied. We continue to perform research in this area to determine optimum TiN thickness value to form the barrier for the boehmite and evaluate the effect of multilayer coatings, which will be discussed in a future paper. Additionally, it is planned to test the coated samples for longer times and at higher temperatures.

\section{Acknowledgement}

This research was sponsored by the U.S. Department of Energy, Office of Nuclear Energy, Nuclear Engineering University Programs (NEUP), under grant number DE-AC07- 05 ID14517. 


\section{References:}

[1] D.Q. Peng, X.D. Bai, F. Pan, H. Sun, B.S. Chen, Influence of aluminum ions implanted on oxidation behavior of ZIRLO alloy at 500 C, Vacuum. 80 (2006) 530-536. doi:10.1016/j.vacuum.2005.08.026.

[2] C. Lemaignan, A.T. Motta, Zirconium Alloys in Nuclear Applications, in: B.R.T. FrostB (Ed.), Mater. Sci. Technol. A Compr. Treat., New York: VCH, 1994: pp. 1-51. doi:10.1016/0149-1970(96)00005-4.

[3] R.S. Daum, Y.S. Chu, a. T. Motta, Identification and quantification of hydride phases in Zircaloy-4 cladding using synchrotron X-ray diffraction, J. Nucl. Mater. 392 (2009) 453463. doi:10.1016/j.jnucmat.2009.04.004.

[4] N.P. Neureiter, B.J. Garrick, R.A. Bari, J. Beard, Percy M., M.Q. Brewster, M.L. Corradini, et al., Lessons learned from the Fukushima nuclear accident for improving safety of U.S. Nuclear Plants, 2014.

[5] L. Hallstadius, S. Johnson, E. Lahoda, Cladding for high performance fuel, Prog. Nucl. Energy. 57 (2012) 71-76. doi:10.1016/j.pnucene.2011.10.008.

[6] K.A. Terrani, S.J. Zinkle, L.L. Snead, Advanced oxidation-resistant iron-based alloys for LWR fuel cladding, J. Nucl. Mater. 448 (2014) 420-435. doi:10.1016/j.jnucmat.2013.06.041.

[7] Shannon M. Bragg-Sitton, Advanced LWR Nuclear Fuel Cladding System Development: Technical Program Plan, 2012.

[8] S.K. Han, Jeon G., Yoon, Joo S., Kim, Hyung J., High temperature wear resistance of (TiAl)N films synthesized by cathodic arc plasma deposition, Surf. Coatings Technol. 8687 (1996) 82-87.

[9] K.L. Lin, M.Y. Hwang, C.D. Wu, The deposition and wear properties of cathodic arc plasma deposition TiAlN deposits, Mater. Chem. Phys. 46 (1996) 77-83. doi:10.1016/0254-0584(96)80134-9.

[10] J.G. Han, K.H. Nam, I.S. Choi, The shear impact wear behavior of Ti compound coatings, Wear. 214 (1998) 91-97. doi:10.1016/S0043-1648(97)00205-6.

[11] Y. Wang, A study of PVD coatings and die materials for extended die-casting die life, Surf. Coatings Technol. 94-95 (1997) 60-63. doi:10.1016/S0257-8972(97)00476-3.

[12] T. Suzuki, D. Huang, Y. Ikuhara, Microstructures and grain boundaries of (Ti,Al)N films, Surf. Coatings Technol. 107 (1998) 41-47. doi:10.1016/S0257-8972(98)00550-7. 
[13] R.D. James, D.L. Paisley, K.A. Gruss, S. Parthasarthi, B.R. Tittmann, Y. Horie, et al., Adhesion evaluation of TiN and (Ti, Al)N coatings on titanium 6Al-4V, Mater. Res. Soc. Symp. Proc. 410 (1996) 377-382.

[14] A. Anders, Surface \& Coatings Technology A review comparing cathodic arcs and high power impulse magnetron sputtering ( HiPIMS ), Surf. Coat. Technol. 257 (2014) 308325. doi:10.1016/j.surfcoat.2014.08.043.

[15] S. PalDey, S. Deevi, Single layer and multilayer wear resistant coatings of (Ti, Al) N: a review, Mater. Sci. Eng. A. 342 (2003) 58-79. doi:10.1016/S0921-5093(03)00473-8.

[16] F. Khatkhatay, L. Jiao, J. Jian, W. Zhang, Z. Jiao, J. Gan, et al., Superior corrosion resistance properties of TiN-based coatings on Zircaloy tubes in supercritical water, J. Nucl. Mater. 451 (2014) 346-351. doi:10.1016/j.jnucmat.2014.04.010.

[17] T. Ikeda, S. Satoh, Phase formation and characterization of hard coatings in the Ti-Al-N system prepared by the cathodic arc ion plating method, Thin Solid Films. 195 (1991) 99110. doi:10.1016/0040-6090(91)90262-V.

[18] A. Anders, Some Applications of Cathodic Arc Coatings, in: Cathodic Arcs From Fractal Spots to Energ. Condens., Springer Science \& Business Media, 2008: pp. 429-490. doi:10.1007/978-0-387-79108-1.

[19] B.F. Coll, R. Fontana, A. Gates, P. Sathrum, (Ti-Al)N advanced films prepared by arc process, Mater. Sci. Eng. A. 140 (1991) 816-824. doi:10.1016/0921-5093(91)90519-S.

[20] J.T.M. De Hosson, N.J.M. Carvalho, Y. Pei, D. Galvan, Electron Microscopy Characterization of Nanostructured Coatings, in: A. Cavaleiro, J.T.M. De Hosson (Eds.), Nanostructured Coatings, Springer Science \& Business Media, 2006: pp. 143-215.

[21] W.-D. Münz, Titanium aluminum nitride films: A new alternative to TiN coatings, J. Vac. Sci. Technol. A Vacuum, Surfaces, Film. 4 (1986) 2717. doi:10.1116/1.573713.

[22] D. Wang, C. Chang, K. Wong, Y. Li, W. Ho, Improvement of the interfacial integrity of ( Ti , Al ) N hard coatings deposited on high speed steel cutting tools, Surf. Coatings Technol. 121 (1999) 388-394.

[23] S.J. Bull, P.R. Chalker, C.F. Ayres, D.S. Rickerby, The influence of titanium interlayers on the adhesion of titanium nitride coatings obtained by plasma-assisted chemical vapour deposition, Mater. Sci. Eng. A. 139 (1991) 71-78. doi:10.1016/0921-5093(91)90599-I.

[24] D.S. Rickerby, S.J. Bull, T. Robertson, A. Hendry, The role of Titanium in the abrasive wear resistance of physically vapour-deposited TiN, Surf. Coatings Technol. 41 (1990) 63-74. 
[25] K.A. Pischow, L. Eriksson, E. Harju, A.S. Korhonen, E.O. Ristolainen, The influence of titanium interlayers on the adhesion of PVD TiN coatings on oxidized stainless steel substrates, Surf. Coatings Technol. 58 (1993) 163-172. doi:10.1016/0257-8972(93)900037.

[26] G.S. Kim, S.Y. Lee, J.H. Hahn, B.Y. Lee, J.G. Han, J.H. Lee, et al., Effects of the thickness of Ti buffer layer on the mechanical properties of TiN coatings, Surf. Coatings Technol. 171 (2003) 83-90. doi:10.1016/S0257-8972(03)00243-3.

[27] P. Salim, J.H.C. da Silva, Enclosure 2 to TXX-01171 ERX-2001-005-NP ZIRLO Cladding and Boron Coating Models for TXU Electric's Loss of Coolant Accident Analysis Methodologies, 2001.

[28] D.B. Scott, Physical and Mechanical Properties of Zircaloy 2 and 4, 1965.

[29] P. Hidnert, Thermal expansion of titanium, J. Res. Natl. Bur. Stand. (1934). 30 (1943) 101. doi:10.6028/jres.030.008.

[30] M. Ahlgren, H. Blomqvist, Influence of bias variation on residual stress and texture in TiAlN PVD coatings, Surf. Coatings Technol. 200 (2005) 157-160. doi:10.1016/j.surfcoat.2005.02.078.

[31] J.A. Sue, A.J. Perry, J. Vetter, Young's modulus and stress of CrN deposited by cathodic vacuum arc evaporation, Surf. Coatings Technol. 68-69 (1994) 126-130. doi:10.1016/0257-8972(94)90149-X.

[32] C. Gautier, J. Machet, Study of the growth mechanisms of chromium nitride films deposited by vacuum ARC evaporation, Thin Solid Films. 295 (1997) 43-52. doi:10.1016/S0040-6090(96)09164-X.

[33] M.K. Kazmanli, M. Ürgen, A.F. Cakir, Effect of nitrogen pressure, bias voltage and substrate temperature on the phase structure of Mo-N coatings produced by cathodic arc PVD, Surf. Coatings Technol. 167 (2003) 77-82. doi:10.1016/S0257-8972(02)00866-6.

[34] W.D. Sproul, Physical vapor deposition tool coatings, Surf. Coatings Technol. 81 (1996) 1-7. doi:10.1016/0257-8972(95)02616-9.

[35] T. Sinkovits, Y. Zhao, R. O'Brien, S. Dowey, X-ray diffraction stress analysis of interrupted titanium nitride films: Combining the $\sin ^{2} \Psi$ and crystallite group methods, Thin Solid Films. 562 (2014) 206-210. doi:10.1016/j.tsf.2014.04.054.

[36] Y. Liu, I. Bhamji, P.J. Withers, D.E. Wolfe, A.T. Motta, M. Preuss, Evaluation of the interfacial shear strength and residual stress of TiAIN coating on ZIRLO ${ }^{\mathrm{TM}}$ fuel cladding using a modified shear-lag model approach, J. Nucl. Mater. (2015). doi:10.1016/j.jnucmat.2015.06.003. 
[37] T. Björk, R. Westergård, S. Hogmark, J. Bergström, P. Hedenqvist, Physical vapour deposition duplex coatings for aluminium extrusion dies, Wear. 225-229 (1999) 11231130. doi:10.1016/S0043-1648(99)00089-7.

[38] V.K. William Grips, H.C. Barshilia, V.E. Selvi, Kalavati, K.S. Rajam, Electrochemical behavior of single layer $\mathrm{CrN}$, TiN, TiAlN coatings and nanolayered TiAlN/CrN multilayer coatings prepared by reactive direct current magnetron sputtering, Thin Solid Films. 514 (2006) 204-211. doi:10.1016/j.tsf.2006.03.008.

[39] www.webmineral.com, (n.d.).

[40] C. Vargel, M. Jacques, D.M.P. Schmidt, Protection Against Corrosion, in: Corros. Alum., Elsevier, 2004: pp. 185-207.

[41] B.Y.R.K. Hart, The formation of films on aluminium, Trans. Faraday Soc. 53 (1956) 1020 .

[42] L. Szparaga, J. Ratajski, a. Zarychta, Multi objective optimization of wear resistant TiAlN and TiN coatings deposite by PVD techniques, Arch. Mater. Sci. Eng. 48 (2011) 33-39.

[43] A. Yilmazbayhan, E. Breval, A.T. Motta, R.J. Comstock, Transmission electron microscopy examination of oxide layers formed on Zr alloys, J. Nucl. Mater. 349 (2006) 265-281. doi:10.1016/j.jnucmat.2005.10.012.

[44] A.T. Motta, A. Yilmazbayhan, M.J.G. da Silva, R.J. Comstock, G.S. Was, J.T. Busby, et al., Zirconium alloys for supercritical water reactor applications: Challenges and possibilities, J. Nucl. Mater. 371 (2007) 61-75. doi:10.1016/j.jnucmat.2007.05.022.

[45] L. Hultman, Thermal stability of nitride thin films, Vacuum. 57 (2000) 1-30. doi:10.1016/S0042-207X(00)00143-3.

[46] A.. Kale, K. Ravindranath, D.. Kothari, P.. Raole, Tribological properties of (Ti,Al)N coatings deposited at different bias voltages using the cathodic arc technique, Surf. Coatings Technol. 145 (2001) 60-70. doi:10.1016/S0257-8972(01)01296-8.

[47] G. Hakansson, J.-E. Sundgren, D. Mcintyre, J.E. Greene, W.-D. Munz, Microstructure and physical properties of polycrystalline metalstable Ti0.5A10.5N alloys grown by D.C. magnetron sputter deposition, Thin Solid Films. 153 (1987) 55-65.

[48] S. Korablov, M. a M. Ibrahim, M. Yoshimura, Hydrothermal corrosion of TiAlN and CrN PVD films on stainless steel, Corros. Sci. 47 (2005) 1839-1854. doi:10.1016/j.corsci.2004.08.009.

[49] A. Abid, R. Bensalem, B.J. Selay, The thermal stability of AlN, J. Mater. Sci. 21 (1986) 1301-1304. doi:10.1016/S0140-6736(00)84859-X. 
[50] Rachel A. Shapiro, Ian M. Younker, and Massimiliano Fratoni, Neutronic performance of accident tolerant fuels, ANS 2013 winter meeting, Transactions of the American Nuclear Society, v. 109(1) pp. 1351-1353 